DOI: 10.20472/IAC.2018.035.007

\title{
ÖMER BEYHAN
}

Necmettin Erbakan University, Ahmet Keleşoğlu Education Faculty, Turkey

\author{
GÖKHAN BAŞ
}

Niğde Ömer Halisdemir University, Education Faculty, Turkey

\section{REVISITING THE EFFECT OF TEACHING OF LEARNING STRATEGIES ON ACADEMIC ACHIEVEMENT: A META-ANALYSIS OF THE FINDINGS}

\begin{abstract}
:
The main purpose of this study was to determine the effect of teaching of learning strategies on students' academic achievement. In this research, meta-analysis method was adopted to determine the effect of teaching of learning strategies on students' academic achievement and the studies in relation with the subject carried out in Turkey were combined. The effect sizes of the studies included in the meta-analysis were compared in regard of instructional level, course type, and publication type variables. This meta-analysis sought an answer to the problem statement of "What kind of effect does teaching of learning strategies have on students' academic achievement levels?" Some certain criteria were taken into consideration to include the studies in the meta-analysis. According to the selected criteria, the experimental studies $(N=11)$ were included in the research. At the end of the research, it was concluded that teaching of learning strategies had a moderate effect size $(d=0.818)$ on students' academic achievement levels. Besides, while the effect sizes obtained as a result of the meta-analysis were compared with respect to instructional level, course type, publication type variables, it was revealed that there were significant differences in regard of the effect sizes of the studies with respect to all variables in the research.
\end{abstract}

\section{Keywords:}

The teaching of Learning Strategies, Academic Achievement, Meta-Analysis, Experimental Studies.

JEL Classification: 120, 121 